\title{
Characterization of monoclonal antibodies against waterfowl parvoviruses VP3 protein
}

Xiuchen Yin ${ }^{1}$, Shumei Zhang ${ }^{1}$, Youlan Gao ${ }^{1}$, Jinzhe Li', Shuyi Tan², Hongyu Liu', Xiaoying Wu', Yuhuan Chen ${ }^{1}$, Ming Liu ${ }^{1 *}$ and Yun Zhang ${ }^{1 *}$

\begin{abstract}
Background: The VP3 protein of goose parvovirus (GPV) or Muscovy duck parvovirus (MDPV), a major structural protein, can induce neutralizing antibodies in geese and ducks, but monoclonal antibodies (MAbs) against VP3 protein has never been characterized.
\end{abstract}

Results: Three hybridoma cell lines secreting anti-GPV VP3 MAbs were obtained and designated 4A8, 4E2, and 2 D5. Immunoglobulin subclass tests differentiated them as IgG2b (4A8 and 4E2) and IgG2a (2D5). Dot blotting assays showed that three MAbs reacted with His-VP3 protein in a conformation-independent manner. A competitive binding assay indicated that the MAbs delineated two epitopes, A and B of VP3. Immunofluorescence assay showed that MAbs 4A8, 4E2, and 2D5 could specifically bind to goose embryo fibroblast cells (GEF) or duck fibroblast cells (DEF) infected with GPV and MDPV. Dot blotting also showed that the MAbs recognized both nature GPV and MDPV antigen. Western blotting confirmed that the MAbs recognized VP3 proteins derived from purified GPV and MDPV particles. The MAbs 4A8 and 2D5 had universal reactivity to heterologous GPV and MDPV tested in an antigen-capture enzyme-linked immunosorbent assay.

Conclusions: Preparation and characterization of these the MAbs suggests that they may be useful for the development of a MAb-capture ELISA for rapid detection of both GPV and MDPV. Virus isolation and PCR are reliable for detecting GPV and MDPV infection, but these procedures are laborious, time-consuming, and requiring instruments. These diagnosis problems highlight the ongoing demand for rapid, reproducible, and automatic methods for the sensitive detection of both GPV and MDPV infection.

Keywords: Monoclonal Antibody, GPV, MDPV, VP3

\section{Background}

Parvovirus infection is widespread in most goose farming countries of Europe and Asia and causes serious economic loss [1,2]. Goose parvovirus (GPV) can cause disease characterized by ascites, enteritis, myocarditis, and hepatitis with high mortality and morbidity in geese (Anser anser) and Muscovy ducks (Cairina moschata) [3-5].

The genomes of GPV and Muscovy duck parvovirus (MDPV) are 5106 nucleotides in length and contain two open reading frames (ORF). The left ORF encodes the regulatory proteins, whereas the right ORF encodes three capsid proteins: VP1, VP2, and VP3. VP1, VP2,

\footnotetext{
*Correspondence: liuming04@126.com; yunzhang03@yahoo.com

${ }^{1}$ State Key Lab of State Key Laboratory of Veterinary Biotechnology, Harbin Veterinary Research Institute, CAAS, Harbin 150001, China

Full list of author information is available at the end of the article
}

and VP3 are derived from the same gene by differential splicing, and VP2 and VP3 are contained within the carboxyl-terminal portion of VP1 [6-8]. The VP1 polypeptides of GPV and MDPV share $88 \%$ amino acid sequence identity [7-9], which allows cross-protection of Muscovy ducks against MDPV infection by vaccination with attenuated GPV [10]. The VP3 protein is the most abundant of the three core proteins [11] and can induce neutralizing antibodies in GPV- or MDPV-infected waterfowls [12]. Recently, a new divergent MDPV (PSU3101 ) has been isolated, which showed $84.5 \%$ sequence identity with other MDPV isolates and $84.6 \%$ identity with GPV isolates [13].

Many methods have been developed for the diagnosis of GPV or MDPV infections, including agar gel precipitation, the virus neutralization test [14], Western blotting assays [15], virus antigen-based enzyme-linked

\section{Biomed Central}


immunosorbent assays (ELISA) [10,16], the VP3 protein based ELISA [17], a plaque neutralization assay [18], an indirect fluorescent antibody test [19], polymerase chain reaction (PCR) for the rapid detection of GPV DNA [20], and quantitative analysis of waterfowl parvovirus by real-time PCR [21]. However, these methods are generally time-consuming and labor-intensive, and require sophisticated instruments. Here, we produced and characterized three MAbs against bacterially expressed VP3 protein of GPV. Contrary to currently available PCR tools, the MAbs could not discriminate between GPV and MDPV infection; however, due to 4A8 and 2D5 universal reactivity to both GPV and MDPV, the MAbs are ideal candidates for both GPV and MDPV clinical diagnosis in an antigen-capture ELISA.

\section{Results}

\section{Production and characterization of MAbs}

Three weeks after cell fusion, the hybridoma cell lines secreting anti-VP3 antibody were screened by means of an ELISA. Three MAbs directed against VP3 were selected and subcloned at least three times using the limiting dilution method. Hybridomas were selected to produce MAbs in mice and the ascitic fluids were used for further characterization. The isotypes of the MAbs were IgG2b (4A8 and 4E2) and IgG2a (2D5). Concentrations of immunoglobulin ranged from 0.40 to $17.53 \mu \mathrm{g} / \mathrm{ml}$.

\section{Effect of denaturation of VP3 on MAb recognition}

The expressed His-VP3 proteins were denatured by boiling in SDS and 2-mercaptoethanol, and subjected to Western blotting; three MAbs still recognized them (Figure 1). To determine whether a VP3 structure is

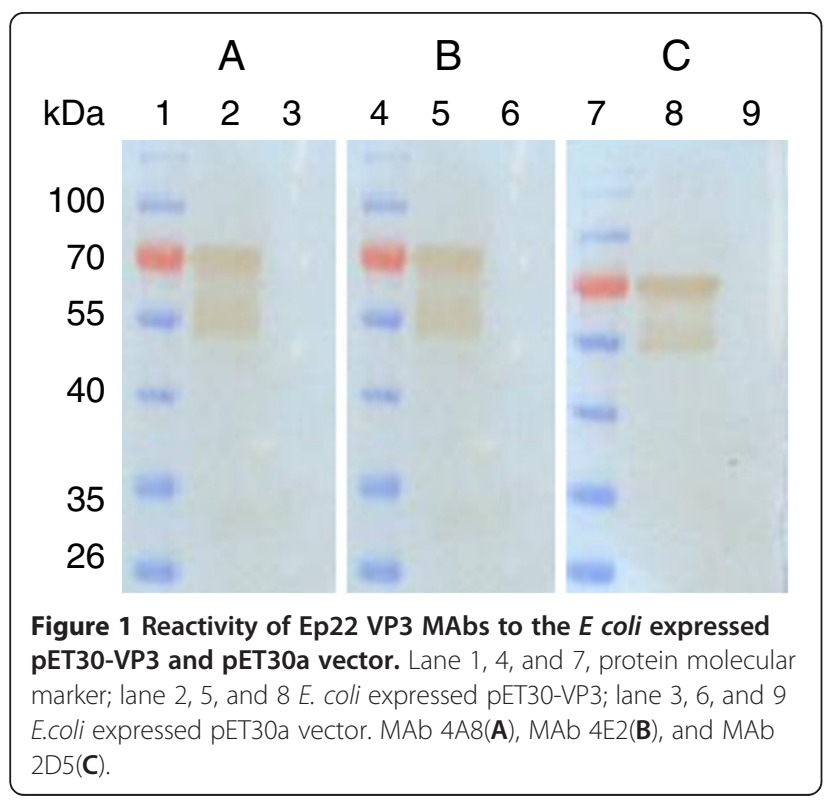

required for antibody binding, antigens containing HisVP3 were examined by using a dot blotting assay. All MAbs recognized the nature structure of His-VP3 in TNE buffer (Figure 2), but did not react with the 6.7 His proteins. Three major proteins (VP 1, VP 2 and VP 3) were identified by SDS-PAGE in a purified Muscovy duck (91, 78 and $58 \mathrm{kDa}$ ) and goose (85, 61 and $57 \mathrm{kDa})$ parvovirus virions [22-24]. Western blotting analysis showed that MAbs reacted with molecular weight of 90 , 77 , and $64 \mathrm{kDa}$ of VP1, VP2, and VP3 from denatured GPV EP22 (represented by Figure 3, lane 2) and MDPV J3D6 (represented by Figure 3, lane 4) antigen, which were similar to VP1, VP2, and VP3 of goose parvovirus and Muscovy duck parvovirus. MAbs did not recognize blank allantoic fluids (represented by Figure 3, lane 3). This result suggested that the MAbs recognized VP3 proteins derived from purified GPV and MDPV particles.

\section{Detection of native VP3 protein by immunofluorescence assay} Immunofluorescence assay was performed on EP22 and J3D6 infected GEF/DEF to assess whether the MAbs recognize the native-form of VP3 protein of GPV and DPV. Three MAbs strongly reacted with EP22 infected GEF cells or J3D6 infected DEF (represented by Figure 4A and B). All uninfected cells showed no reaction to any MAbs (represented by Figure $4 \mathrm{C}$ ). Immunofluorescence assay also indicates that the MAbs bound to the authentic viral VP3 protein, which located predominantly within the nuclei without affecting the nucleoli and rarely within the cytoplasm of infected cells, which is consistent with previous report [22,23]. In some cells GPV/MDPV appeared as granules scattered throughout the nucleus (indicated by red arrow), while in other cells GPV/MDPV were distributed homogeneously in nuclei (indicated by purple arrow or in Figure 4B).

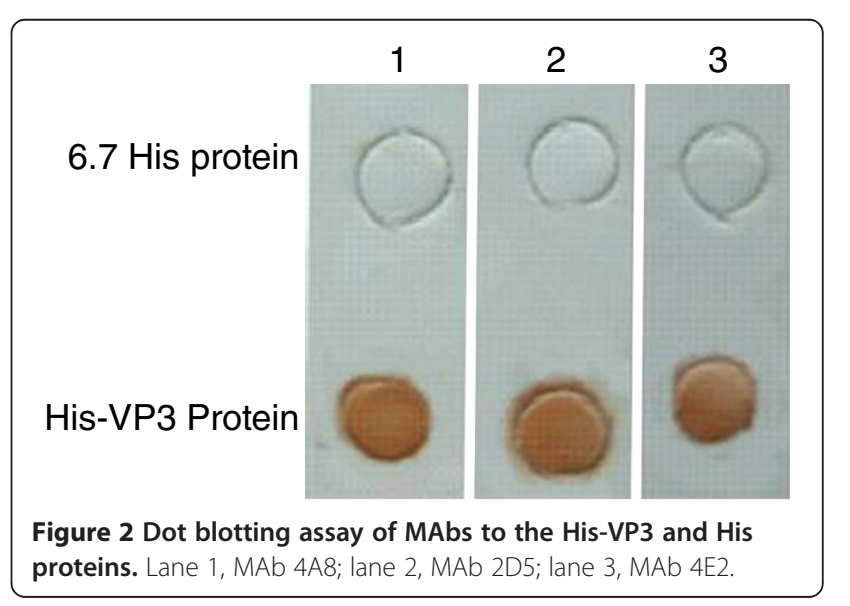




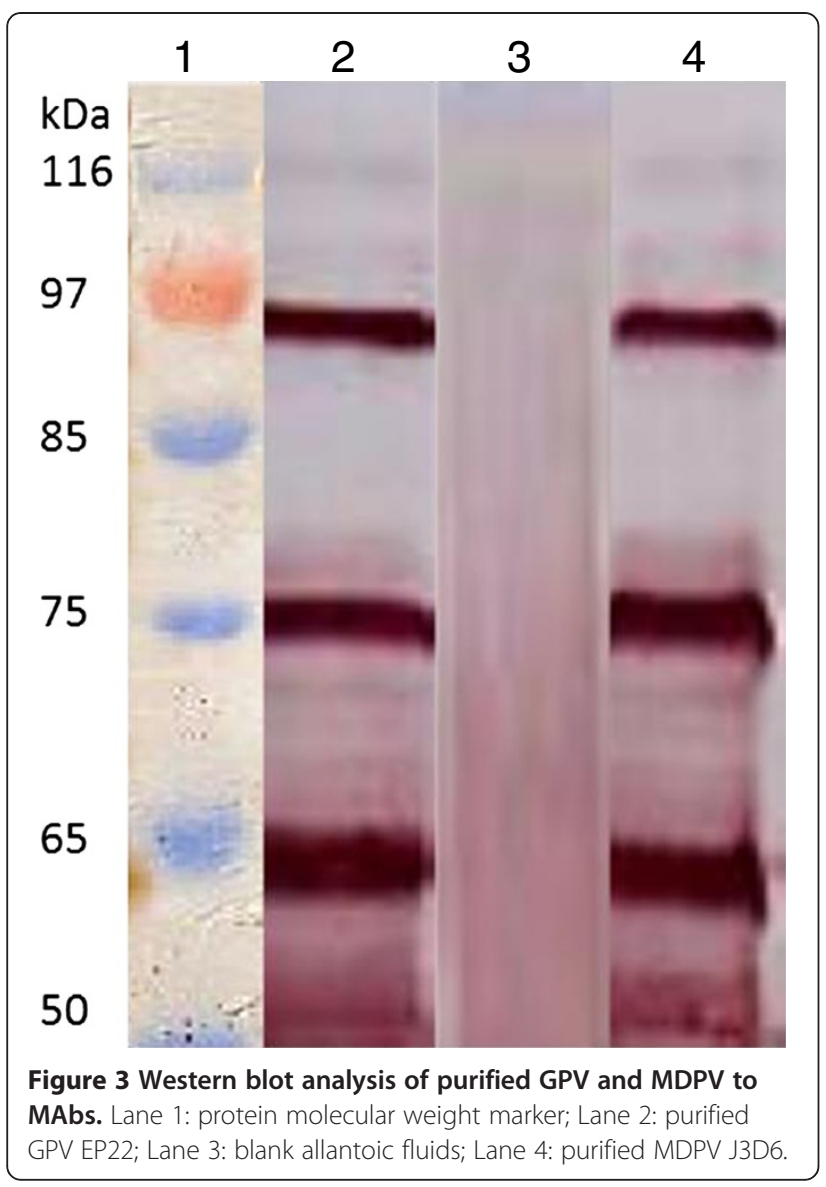

Effect of native structure of VP3 on MAbs recognition Dot blotting assays showed that three MAbs recognized both GPV and DPV native particles, while blank allantoic fluids were not detected by any MAbs (Figure 5).

\section{Avidity of the MAbs to VP3}

The amount of MAbs bound to the VP3 proteins can be quantified within the linear range of absorbance. This offers an estimation of the relative avidity of MAbs for

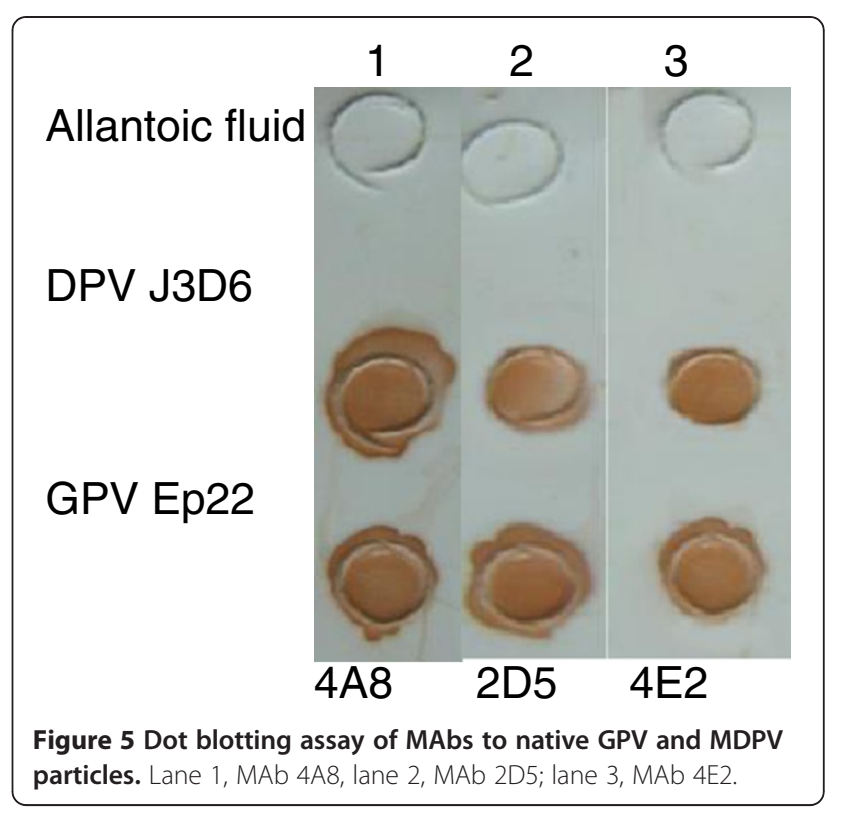

their binding proteins. The binding degrees of the MAbs to the His-VP3, using ELISA titration, indicated that the three MAbs saturated fat dilutions ranging from $10^{-1}$ to $10^{-1.6}$. The three MAbs retained their binding capacity after coupling to HRP, and the dilution range of saturation was $10^{1}$ to $10^{2}$. No saturation was apparent with the remaining HRP-MAbs (data not shown).

\section{Epitopes mapping}

The appropriate concentrations for the competitive binding assay were determined by using the dose-response curves plotted for the unconjugated and HRPconjugated MAbs (data not shown). Each of the three MAbs was used both as a competitor and as an HRPconjugated probe. The percentage of competition was $100 \%$ in the presence of a saturating unlabeled homologous antibody. Two distinct epitopes on VP3 were found and designated $\mathrm{A}$ and $\mathrm{B}$ (Table 1). MAb 4A8 recognized epitope A, whereas 4E2 and 2D5 recognized epitope B.

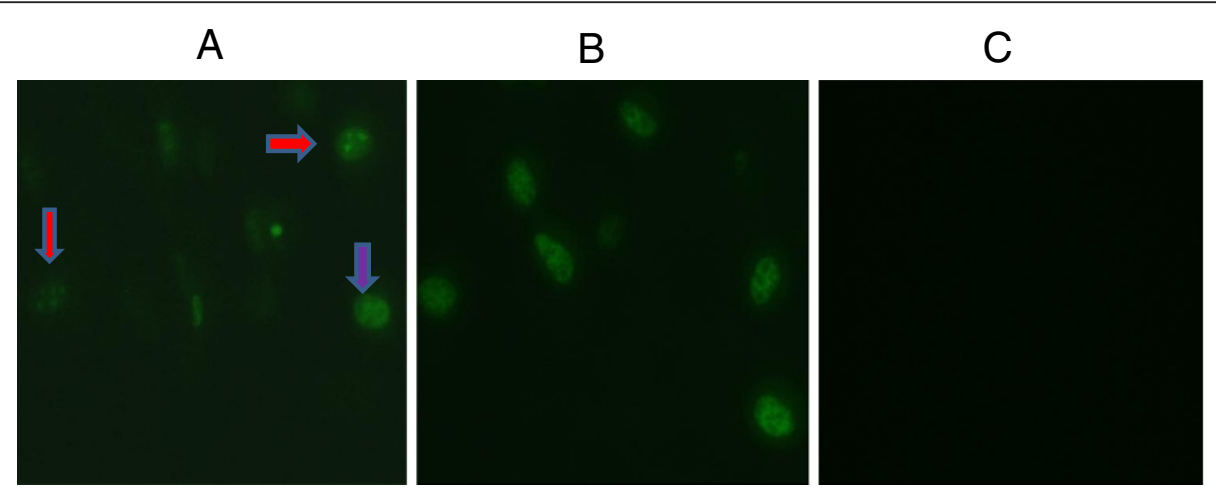

Figure 4 Detection of VP3 protein by indirect immunofluorescence assay on cells infected with EP22 and J3D6. A: GPV infected GEF, B: MDPV infected MDF, C: Mock infected cells. No special fluorescence was found on normal cells $(400 \mathrm{X})$. 
Table 1 Competitive binding of MAbs for the VP3 protein

\begin{tabular}{lccc}
\hline Competitor & \multicolumn{3}{c}{ HRP-labeled MAbs } \\
\cline { 2 - 4 } & $\mathbf{4 A 8}$ & 4E2 & 2D5 \\
\hline Epitope A & & -- & -- \\
4A8 & ++ & & \\
Epitope B & & ++ & ++ \\
4E2 & -- & ++ & ++ \\
2D5 & -- & & \\
\hline
\end{tabular}

\section{Detection of VP3 antigens}

MAbs 4A8 and 2D5, which recognized epitopes A and $\mathrm{B}$, respectively were selected to test their cross-reactivity with other heterologous GPV strains (G3, GD, and HE) or MDPV (J3D6 and KL) in the ELISA. The relative binding to heterologous GPV or MDPV isolates was expressed as a percentage of the absorbance obtained with GPV EP22, which was set at 100. Binding was rated as strong if it was more than $50 \%$, significant if it was $25 \%-50 \%$, and negative if it was less than $25 \%$. The results indicated that the VP3 in the cell extracts prepared from CGBQ cells infected with heterologous GPV strains or from MDEF cell infected with DPV was captured by the anti-VP3 antiserum. The binding rated for GPV and MDPV were $100 \%$ and there were no appreciable differences for GPV in the binding of the different MAbs tested. As expected, negative results were obtained with mock-infected CGBQ cells or DEF cells $(<25 \%)$. MAbs 4A8 and 2D5 strongly recognized all tested GPV and MDPV strains, suggesting that epitopes $\mathrm{A}$ and $\mathrm{B}$ are commonly present on the VP3 of GPV and MDPV strains and indicating that 4A8 and 2D5 are suitable for detecting GPV and MDPV isolates.

\section{Discussion}

Here, we developed and characterized three MAbs against goose parvovirus VP3 protein. Our results show that antigen preparations containing the expressed HisVP3 protein of GPV could induce the production of MAbs. After screening and sub-cloning, three MAbs against His-VP3 were isolated and characterized. Western blotting and immunofluorescence assay indicated that the MAbs bound to the authentic viral VP3 protein of GPV and MDPV and that this protein localized mainly in the nucleus of infected cells, which is consistent with a previous report [22,23]. The MAbs bound to the His-VP3 in its native conformation, and when SDS and 2-mercaptoethanol were used to denature the His-VP3 protein, this binding was retained, indicating that the epitopes were not affected by breaking of disulfide bonds. This finding suggests that the MAbs binding was conformation-independent. Competitive binding assays were used to determine the epitopes recognized by the MAbs based on the notion that a
MAb binding to a specific site can block the attachment of another MAb to the same site. Two epitopes, A and $\mathrm{B}$, almost completely inhibited the binding of HRPcoupled MAbs recognizing the same epitope, but no competition was obtained among MAbs recognizing epitope A or B. Dot blotting analysis showed that the epitopes on the VP3 recognized by three MAbs were also present on the native viral VP3 of GPV and DPV particles, which is consistent with immunofluorescence assay analysis. By the immunofluorescence assay, it could also identify the GPV/MGPV antigen with MAbs because of its distinctive nuclear localization within infected cells, which consistent with previous report [22]. A similar finding was obtained when MAbs specificities were analyzed by Western blotting. Three major proteins (VP1, VP2 and VP3) MW are in consistent with previously reports of Muscovy duck (91, 78 and $58 \mathrm{kDa}$ ) and goose (85, 61 and $57 \mathrm{kDa})$ parvovirus virions [22-24].

Whether epitope A or B is involved in any biological function has not yet been determined; however, these epitopes, are highly conserved among GPV and MDPV strains, as the MAbs recognized both epitopes on all field strains tested. It has been suggested that the epitopes recognized by B19 [25] are involved in heparan sulfate binding. The region containing the epitope might function as the primary receptor attachment site of B19, yet it does not correspond to the globoside binding site [26]. This reason for this discrepancy requires clarification. Accordingly, to determine whether VP3 of GPV/ MDPV is involved in heparan sulfate binding, we are currently preparing deletion mutant proteins of GPV/ MDPV VP3 to assess with the MAbs described here.

Three MAbs successfully detected the native-form of the VP3 protein in infected cells, as well as in viral particles. Therefore, these MAbs may be useful in the development of sensitive methods to detect GPV and MDPV, such as immunoblot assays, immunofluorescence assays, and antigen-capture ELISA. Antigen-capture ELISA using antivirus antibodies is ideal for large screening, quantitative analysis of viral antigens or virus titres because of its high sensitivity, reproducibility, and automation. In this study, we generated three positive clones that secreted specific and highly reactive antibodies against VP3 protein for use in diagnostic methods. MAb-capture ELISA clearly differentiated between GPV-/MDPV- and mock-infected samples, as demonstrated by absorbance values, suggesting that non-specific reactions could be markedly reduced in a MAb-capture ELISA. Two of the MAbs (4A8 and 2D5) recognized GPV and MDPV VP3 at different sites that were highly conserved in all GPV and MDPV strains tested. Thus, a MAb-capture ELISA using MAbs 4A8 and 2D5 would appear to be an acceptable future screening method for the detection of GPV and MDPV in infected birds. 


\section{Conclusion}

In summary, the results of this study provide important information about MAbs against the GPV VP3 protein. In particular, the MAbs could contribute to the development of a MAb-capture ELISA for rapid detection of GPV and MDPV. GPV and DPV antigen could be detected with these MAbs in GPV infected cells in Immunofluorescence assay. Although virus isolation and PCR are reliable methods to detect GPV and MDPV infection, they are laborious, time-consuming, and requiring specialized instruments. These diagnosis problems highlight the need for alternative rapid, reproducible, and automatic methods to detect GPV and MDPV.

\section{Methods}

\section{Cells and viruses}

Heterologous goose parvoviruses EP22, G3, GD, HE, and Muscovy duck parvovirus (MDPV) J3D6 were used in this study. The GPV Ep22, G3, GD, and HE strains were isolated from the livers dead geese with hepatitis in China in 2001, 1995, 1989, and 2007, respectively, as described previously [27]. MDPV J3D6 and KL strains were isolated from dead Muscovy ducks in 1999 and 2008. VP3 gene of EP22, G3, GD, and HE diverge 4.1 to $4.7 \%$ at amino acids level. VP3 of J3D6 and KL showed 85.9\%-88.7\% identities to those of GPV. GPV were propagated in goose CGBQ cells (AATC CCL-169) or goose embryo fibroblast cells (GEF) or in the allantoic sacs of 14-day-old embryonated goose eggs. MDPV J3D6 and KL was propagated in 13-day-old Muscovy duck embryonated eggs.

\section{Virus purification}

The allantoic fluids containing EP22 and J3D6 were centrifuged at $20000 \times g$ for $15 \mathrm{~min}$. The supernatants were layered onto $30 \%(\mathrm{w} / \mathrm{w})$ sucrose solution and concentrated by ultracentrifugation $\left(109000 \times g, 10 \mathrm{~h}, 4^{\circ} \mathrm{C}\right)$. The pellets were suspended in PBS, clarified at $5000 \times g$ for $20 \mathrm{~min}$ and ultracentrifuged at $109000 \times g$ for $2.5 \mathrm{~h}$. The purified viruses were stored at $-20^{\circ} \mathrm{C}$ until used.

\section{Antigen preparation}

The VP3 protein used for the production and characterization of MAbs was synthesized in Escherichia coli BL21 (DE3) as described previously [17]. The expressed His-VP3 and 6.7-kDa His tag proteins were purified by using a Ni-NTA kit (Qiagen, Valencia, CA). The $6.7-\mathrm{kDa}$ His tag protein was used as a negative control during screening for specific antibodies to VP3 in an ELISA.

\section{Monoclonal antibodies production}

BALB/C mice (Harbin Veterinary Experimental Central) were immunized intraperitoneally with $30 \mu \mathrm{g}$ of antigen containing the VP3 fusion protein in complete Freund's adjuvant and boosted twice with the same amount of antigen in incomplete Freund's adjuvant at 2-week intervals. Six weeks after the initial immunization and 4 days before the mice were sacrificed for the preparation of hybridomas, a final boost was given via the same route with $30 \mu \mathrm{g}$ of the same antigen. MAbs were produced by using techniques similar to those described previously [28]. Briefly, spleens were removed from the immunized mice, and their splenocytes were fused with NS1 myeloma cells. Hybridoma cell lines secreting antibodies against the VP3 protein were screened and subcloned at least three times by use of a limiting dilution method and ascitic fluids were prepared with the cloned hybridomas in $\mathrm{BALB} / \mathrm{C}$ mice. All mice were maintained in the animal facility at Harbin Veterinary Research Institute under standard conditions prescribed by the Institutional Guidelines. The study protocol was approved by the Institutional Animal Care and Use Committee.

\section{Serological screening}

Hybridoma culture supernatants or mouse ascetic fluids were screened for antibodies in an indirect ELISA as described for the antibody binding assay. Antibodies that bound to the VP3 protein but failed to bind the $6.7-\mathrm{kDa}$ protein were selected for sub-cloning.

\section{Isotyping}

Isotypes of the produced MAbs were determined by using a Mouse Immunoglobulin isotyping kit (Zymed Laboratories, Inc.) according to the manufacturer's instructions.

\section{Western blotting and dot blotting assays}

The samples of expressed His-VP3/His proteins and purified GPV EP22 and MDPV J3D6 were denatured by boiling in SDS and 2-mercaptoethanol. The boiled samples were subjected to 10\% SDS-PAGE and transferred to nitrocellulose membranes for Western blotting analysis. The membranes were probed with different MAbs followed by a secondary HRP-conjugated goat antimouse antibody (KPL, MD, USA). The purified GPV and MDPV antigen or blank allantoic fluids (as a negative control) were used for Western blotting assays. The native antigens containing His-VP3 and the 6.7 His protein (as a negative control) were used for dot blotting assays. The membranes were then probed with the same MAbs as for Western blotting assays.

\section{Detection of native VP3 protein by immunofluorescence assay}

GEF and DEF infected with Ep22 and J3D6 strain (at 10 M.O.I. TCID50/cell), respectively, incubated at $37^{\circ} \mathrm{C}$ for $48 \mathrm{~h}$. The cells were fixed with cold methanol for 
10 min and then probed with different anit-VP3 MAbs and negative normal mouse serum for $1 \mathrm{~h}$ at $37^{\circ} \mathrm{C}$. Bound antibodies were visualized using fluorescent conjugated antibodies against mouse IgG (1:500 dilutions) under a fluorescence microscope.

\section{Effect of native structure of VP3 on MAbs recognition}

To determine if a native GPV or MDPV particles could be recognized by three MAbs, the purified GPV EP22 and MDPV J3D6 particles (about $1 \mu \mathrm{g}$ ) and blank allantoic fluids as negative control were spotted onto nitrocellulose membranes for dot blotting assays.

\section{Coupling of horseradish peroxidase to MAbs}

Immunoglobulin fractions were isolated from ascetic fluids by precipitation at $4^{\circ} \mathrm{C}$ with an equal volume of saturated ammonium sulfate $(\mathrm{pH} 7.0)$, and then purified by using an affinity column of protein G-agarose (Boehringer Mannheim). Antibodies were coupled to HRP by means of the periodate method [29] and stored at $-20^{\circ} \mathrm{C}$.

\section{Determination of MAbs titres}

The titers of the MAbs were determined by using an ELISA. The purified His-VP3 protein $(0.1 \mu \mathrm{g})$ was coated onto plate wells at $37^{\circ} \mathrm{C}$ for $2 \mathrm{~h}$. The plates (Nunc MaxiSorp ${ }^{\circledR}$ flat-bottom 96 well plate) were then washed three times with washing buffer $(0.01 \mathrm{M}$ phosphatebuffered saline, pH 7.2, 0.05\% Tween 20) and blocked with $100 \mu \mathrm{l}$ of TNE buffer containing $2.5 \%$ bovine serum albumin. After washing, two-fold serial dilutions of $1 \mu \mathrm{g} / \mathrm{ml}$ uncoupled or HRP-coupled MAbs were added and incubated for $1 \mathrm{~h}$. For uncoupled MAbs, an additional $50 \mu \mathrm{l}$ of HRP-coupled goat anti-mouse antibodies (KPL, MD, USA) was added. Absorbance was read at $405 \mathrm{~nm}$ with a Microplate Reader (BIO-RAD). The level of binding for the relative activity assessment was measured from the resulting dose-response curve.

\section{Antibody binding assay}

For the competitive binding assay, the amount of MAb binding in the ELISA was determined for MAbs uncoupled or coupled with HRP [30]. Briefly, for HRPunconjugated MAb determination, ELISA plates were coated with $0.1 \mu \mathrm{g}$ of purified VP3 per well at $37^{\circ} \mathrm{C}$ for $2 \mathrm{~h}$. After washing, $100 \mu \mathrm{l}$ of TNE buffer containing $2.5 \%$ bovine serum albumin was added to each well to saturate all unbound sites. After washing, $100 \mu \mathrm{l}$ of purified MAb serially diluted with TNE buffer containing $1 \%$ bovine serum albumin was added and incubated for $2 \mathrm{~h}$ at $30^{\circ} \mathrm{C}$. After washing, $50 \mu \mathrm{l}$ of a 1:500 dilution of HRPconjugated goat anti-mouse IgG serum was added and incubated for another $1 \mathrm{~h}$. The enzymatic activity was determined after 20 min of incubation by the addition of
$30 \mathrm{ml}$ of $1 \%$ sodium azide. Absorbance was measured at $405 \mathrm{~nm}$. For HRP-conjugated MAb determination, the same procedures were carried out except that HRPconjugated MAbs were directly added to the antigencoated plates without using the HRP-conjugated goat anti-mouse antiserum. The level of maximum binding for the relative activity assessment and the MAb concentration at which $50 \%$ binding occurred were obtained from the resulting dose-response curve.

\section{Competitive binding assay}

The competitive binding assay was performed similarly to the procedures described above, except that a mixture of the HRP-conjugated MAbs was used at twice the concentration, giving half-maximal binding. Unconjugated, competing antibodies at different concentrations were also added simultaneously. The competition between two MAbs for the same site was correlated to their relative avidities and concentrations. A spectrum of doserelated interference was tested. Non-specific binding without antigens was used to represent the background. The degree of competitive binding was measured from the absorbance at $405 \mathrm{~nm}$ in the presence or absence of unconjugated competing antibodies. Competition was rated as strong $(++)$ if it was more than $60 \%$, significant $(+)$ if it was more than $30 \%$, and negative $(-)$ if it was less than $30 \%$.

\section{Cross-reactivity of MAbs to heterologous GPV strains}

To study the cross-reactivity of the MAbs for various GPV and MDPV strains in an antigen-captured ELISA, we tested three GPV (G3, GD, and HE) and MDPV (J3D6 and KL) field isolates. MAbs (4A8 and 2D5) were used to prepare an antigen-capture ELISA and compared with a polyclonal antibody against GPV EP22. Briefly, $100 \mu \mathrm{l}$ of mouse anti-VP3 polyclonal antibodies (1:200) was coated onto ELISA plates. After washing and blocking, $100 \mu \mathrm{l}$ of cell extracts of GEF or DEF infected with GPV or MDPV isolates or from mock-infected cells was added and incubated for $1 \mathrm{~h}$ at $37^{\circ} \mathrm{C}$. For the MAb reactions, $50 \mu \mathrm{l}$ of HRP-conjugated MAbs (1:1000) was added as the primary antibody. To determine whether the VP3 present in each cell extract from cells infected with each GPV and MDPV isolate was captured by the anti-VP3 antiserum, goose antiserum against GPV EP22 and HRP-coupled goat anti-goose antiserum were used as a primary and secondary antibodies, respectively. Absorbance was measured at $405 \mathrm{~nm}$. Binding to the heterologous virus was expressed as a percentage of the absorbance obtained with GPV EP22, which was set at 100 . Binding was rated as strong if it was more than $50 \%$, significant if it was $25 \%-50 \%$, and negative if it was less than $25 \%$. 


\section{Abbreviations}

GPV: Goose parvovirus; MDPV: Muscovy duck parvovirus; MAb: Monoclonal antibody; ELISA: Enzyme-linked immunosorbent assay; PCR: Polymerase chain reaction.

\section{Competing interests}

The authors declare that they have no competing interests.

\section{Authors' contributions}

$M L$ and $Y Z$ are responsible for the research design and the writing of this manuscript. XCY, SMZ, JZL, SYT, HYL, XYW, and YHC performed the MAbs preparation and characterization, cloning, and sequencing of VP3 of the EP22 isolate. All authors read and approved the final manuscript. XCY and $\mathrm{SMZ}$ contribute equally to this paper.

\section{Acknowledgements}

This work was supported by the Modern Agro-industry Technology Research System (CARS-43-10), Chinese Special Fund for Agro-scientific Research in the Public Interest (201003012), and the National Natural Science Foundation of China (31072132).

\section{Author details}

'State Key Lab of State Key Laboratory of Veterinary Biotechnology, Harbin Veterinary Research Institute, CAAS, Harbin 150001, China. ${ }^{2}$ Hainan Key Lab of Tropical Animal Reproduction \& Breeding and Epidemic Disease Research, Haikou 571100, China.

Received: 23 March 2012 Accepted: 30 October 2012

Published: 23 November 2012

\section{References}

1. Gough RE: Goose parvovirus infection, Dis Poultry. Ames. lowa: lowa State University Press; 1991:684-690.

2. Kisary J: Derzsy's disease of geese, Virus Infections of Vertebrates. Vol 4th edition. Amsterdam: Elsevier; 1985:157-162.

3. Takehara K, Nishio T, Hayashi Y, Kanda J, Sasaki M, Abe N, Hiraizumi M, Saito S, Yamada T, Haritani M: An outbreak of goose parvovirus infection in Japan. J Vet Med Sci 1995, 57:777-779.

4. Gough RE: Goose parvovirus infection. In Dis Poultry. 11th edition. Edited by Saif YM, Barnes HJ, Glisson JR, Fadly AM, McDougal LR, Swayne DE. Ames, IA: lowa State Univ. Press; 2003:367-374.

5. Jansson DS, Feinstein R, Kardi V, Mató T, Palya V: Epidemiologic investigation of an outbreak of goose parvovirus infection in Sweden. Avian Dis 2007, 51:609-613.

6. Zádori Z, Erdei J, Nagy J, Kisary J: Characteristics of the genome of goose parvovirus. Avian Pathol 1994, 23:359-364.

7. Zádori Z, Stefancsik R, Rauch T, Kisary J: Analysis of the complete nucleotide sequences of goose and muscovy duck parvoviruses indicates common ancestral origin with adeno-associated virus 2 Virology 1995, 212:562-573.

8. Tatar-Kis T, Mato T, Markos B, Palya V: Phylogenetic analysis of Hungarian goose parvovirus isolates and vaccine strains. Avian Pathol 2004 33:438-444.

9. Chu CY, Pan MJ, Cheng JT: Genetic variation of the nucleocapsid genes of waterfowl parvovirus. J Vet Med Sci 2001, 63:1165-1170.

10. Jestin V, Le Bras MO, Cherbonnel M, Le Gall G, Bennejean G: Isolement de virus de la maladie de Derzsy très pathogens chez le canard de Barbarie. Recueil de Mèd Vètèinaaire 1991, 167:849-857.

11. Le Gall-Reculé $G$, Jestin V: Biochemical and genomic characterization of Muscovy duck parvovirus. Arch Virol 1994, 139:121-131.

12. Le Gall-Reculé $G$, Jestin V, Chagnaud P, Blanchard $P$, Jestin A: Expression of muscovy duck parvovirus capsid proteins (VP2 and VP3) in a baculovirus expression system and demonstration of immunity induced by the recombinant proteins. J Gen Virol 1996, 77:2159-2163.

13. Poonia B, Dunn PA, Lu H, Jarosinski KW, Schat KA: Isolation and molecular characterization of a new Muscovy duck parvovirus from Muscovy ducks in the USA. Avian Pathol 2006, 35:435-441.

14. Gough RE: Application of the agar gel precipitation and virus neutralization tests to the serological study of goose parvovirus. Avian Pathol 1984, 13:501-509.
15. Wang CY, Shieh HK, Shieh JH KOCY, Chang PC: Expression of capsid proteins and non-structural proteins of waterfowl parvoviruses in Escherichia coli and their use in serological assays. Avian Pathol 2005, 34:376-382.

16. Kardi V, Szegletes E: Use of ELISA procedures for the detection of Derzsy's disease virus of geese and of antibodies produced against it. Avian Pathol 1996, 25:25-34.

17. Zhang Y, Li YF, Liu M, Zhang DB, Guo DC, Liu CG, Zhi HD, Wang XM, Li G, Li N, Liu SG, Xiang WH, Tong GZ: Development and evaluation of a VP3-ELISA for the detection of goose and Muscovy duck parvovirus antibodies. J Virol Meth 2010, 163:405-409.

18. Takehara K, Hyakutake K, Imamura T, Mutoh K, Yoshimura M: Isolation, identification, and plaque titration of parvovirus from Muscovy ducks in Japan. Avian Dis 1994, 38:810-815.

19. Takehara K, Nakata T, Takizawa K, Limn CK, Mutoh K, Nakamura M: Expression of goose parvovirus VP1 capsid protein by a baculovirus expression system and establishment of fluorescent antibody test to diagnose goose parvovirus infection. Arch Virol 1999, 144:1639-1645.

20. Limn CK, Yamada T, Nakamura M, Takehara K: Detection of goose parvovirus genome by polymerase chain reaction: distribution of goose parvovirus in Muscovy ducklings. Virus Res 1996, 42:167-172.

21. Woźniakowski G, Samorek-Salamonowicz E, Kozdruń W: Quantitative analysis of waterfowl parvovirus in geese and Muscovy ducks by real-time polymerase chain reaction: correlation between age, clinical symptoms and DNA copy number of waterfowl prvoviruses. BMC Vet Re 2012, 15:8-29.

22. Alexandrov M, Alexandrova R, Alexandrov I, Zacharieva S, Lasarova S, Doumanova L, Peshev R, Donev T: Fluorescent and electron-microscopy immunoassays employing polyclonal and monoclonal antibodies for detection of goose parvovirus infection. J Virol Meth 1999, 79:21-32.

23. Ju HY, Wei N, Wang $Q$, Wang $C Y$, Jing ZQ, Guo L, Liu DP, Gao MC, Ma B, Wang JW: Goose parvovirus structural proteins expressed by recombinant baculoviruses self-assemble into virus-like particles with strong immunogenicity in goose. Biochem and Bioph Res Commu 2011 409:131-136.

24. Le Gall-Recule G, Jestin V: Biochemical and genomic characterization of muscovy duck parvovirus. Arch Virol 1994, 139:121-131.

25. Kaufmann B, Simpson AA, Rossmann MG: The structure of human parvovirus B19. Proc Natl Acad Sci USA 2004, 101:11628-11633. 28.

26. Chipman PR, Agbandje-McKenna M, Kajigaya S, Brown KE, Young NS, Baker TS, Rossmann MG: Cryo-electron microscopy studies of empty capsids of human parvovirus B19 complexed with its cellular receptor. Proc Natl Acad Sci USA 1996, 93:7502-7506.

27. Schettler $\mathrm{CH}$ : Isolation of a highly pathogenic virus from geese with hepatitis. Avian Dis 1970, 15:323-325.

28. Liu M, Chen XD, Wang Y, Zhang Y, Li YF, Wang YF, Shen N, Chen H: Characterization of monoclonal antibodies against Muscovy duck reovirus $\sigma B$ protein. Virology J 2010, 7:133.

29. Wilson MB, Nakane PK: Recent developments in the periodate method of conjugating horseradish peroxidase (HRPO) to antibodies, In immunofluorescence and related staining techniques. North Holland, New York: Elsevier; 1978:215-224.

30. Hou HS, Su YP, Shieh HK, Lee LH: Monoclonal antibodies against different epitopes of nonstructural protein $\sigma N S$ of avian reovirus $\$ 1133$ Virology 2001, 282:161-175.

doi:10.1186/1743-422X-9-288

Cite this article as: Yin et al:: Characterization of monoclonal antibodies against waterfowl parvoviruses VP3 protein. Virology Journal 2012 9:288. 